\title{
AUTHORITY AND TRUST: REFLECTIONS ON LINDA ZAGZEBSKI'S EPISTEMIC AUTHORITY
}

\section{JOHN COTTINGHAM}

University of Reading

\section{INTRODUCTION}

Our modern egalitarian and individualistic age is suspicious of authority, and in recent times there have been almost daily reports in the press of cases where trust in various authorities, including financial, governmental, political and religious, has been found to have been abused or misplaced. Such disappointments seem to bolster the case for withholding trust in external authority and falling back on one's own resources. But if the lessons from Linda Zagzebski’s groundbreaking work are accepted, ${ }^{1}$ selfreliance turns out to be a confused and probably incoherent ideal (this is the critical or negative part of her thesis); and (more positively) the rational and self-reflective person is committed to believing and acting on authority. In the second half of this short discussion paper I shall raise some possible concerns about Zagzebski's positive case for reliance on authority, focussing on the moral and religious spheres. First however, let me say something about the negative part of Zagzebski's work, her critique of self-reliance. Since I find this wholly convincing, I shall confine myself to some supplementary observations, mainly to do with the historical context in which her critique is located.

\section{FORWARDS AND BACKWARDS FROM KANT}

One of the many virtues of Epistemic Authority is the light it casts on the genealogy of our modern philosophical culture. Zagzebski identifies Kant as the pivotal figure here; but her analysis goes far beyond the standard acknowledgment of his role in that upheaval in thought we know as the

${ }^{1}$ Linda Trinkaus Zagzebski, Epistemic Authority: A Theory of Trust, Authority, and Autonomy in Belief (Oxford: Oxford University Press, 2012). 
'Enlightenment'. Kant's notion of the rational will as selbstgesetzgebend, 'giving the law to itself', 'is often taken to be crucial in the modern shift from understanding morality as obedience to law to understanding it as self-governance. ${ }^{3}$ But Zagzebski brings out what one might call the 'Janus-faced' character of this concept of the rational will: it looks backward to the traditional idea of reason as the foundation of authority, yet also forward to conceptions which accord primacy to individual choice as the ultimate source of normativity. ${ }^{4}$ To put the matter more precisely, what gradually gathers speed after Kant is not just a shift from a rationalistic to a voluntarist conception of the basis of morality, but a further shift from understanding morality as grounded in something outside the self, which I am required to acknowledge as constraining my will, towards thinking of it as depending in the end on no more than my own individual decisions, or my own chosen self-conception.

The effects of this shift are clearly discernible, I think, in the language that has become so characteristic of the moral philosophizing of recent times. At first sight, to be sure, much of this language appears to accord primacy to the authority of reason, as for example in the 'constructivism' of Christine Korsgaard, which seeks to ground objectivity by reference to the rational procedures whereby we arrive at moral conclusions. But this approach still leaves open the question of what gives the moral values and maxims so arrived at their normative clout, or their ultimate authority over us. Korsgaard's answer to this, in the end, appears to be that if we were to violate them we would lose our sense of integrity and self-worth; ${ }^{5}$ and here she seems partly to echo an earlier suggestion of Bernard Williams that the normative force of obligations derives ultimately from 'the ethos, the projects, the individual nature of the agent.' ${ }^{6}$ Yet, as recent critics have

${ }^{2}$ Autonomy, for Kant, is 'the basis of the dignity of human nature and of every rational nature', according to which our will must be considered as selbstgesetzgebend ('giving the law to itself'). Groundwork of the Metaphysic of Morals [Grundlegung zur Metaphysik der Sitten, 1785], Ch 2; Akademie edition (Berlin: Reimer/De Gruyter, 1900-), Vol. IV, pp. 436, 431; transl. T. E. Hill Jr and A. Zweig (Oxford: Oxford University Press, 2003), pp. 236, 232.

${ }^{3}$ A shift traced out by J. B. Schneewind in The Invention of Autonomy (Cambridge: Cambridge University Press, 1998), cited in Zagzebski, Epistemic Authority, p. 19.

${ }^{4}$ Cf. Zagzebski, Epistemic Authority, pp. $23 \mathrm{ff}$.

${ }^{5}$ Christine Korsgaard, The Sources of Normativity (Cambridge: Cambridge University Press, 1996), p. 102.

${ }^{6}$ Compare Bernard Williams, Shame and Necessity (Berkeley: University of California Press, 1993), Ch. 5, p. 103. 
pointed out, putting it this way seems to get things backwards. The reason I couldn't with integrity live with myself if I betrayed a comrade is not that I have a certain conception of myself I can't give up; rather it is because I recognize something objectively morally repugnant about betrayal. ${ }^{7}$ Or if this is denied, and my own self-conception or 'self-constitution'8 is supposed to be the bedrock on which normativity rests, the question arises as to why some values should take precedence over others in determining how I conceive of or constitute myself. Though it is not her purpose to analyse these recent debates, Zagzebski's framework seems to me to cast a great deal of light on what is driving them, especially when she identifies a gradual 'degeneration' from the (initially arguably benign) Kantian conception of the rational will to a Nietzschean-style conception in which 'my own will, unconstrained by anything, including reason, is the only authority over me.9

Moral self-reliance, construed in this latter way, turns out to be a very dubious notion, and one which, as Zagzebski shows, cannot properly be laid at Kant's door. For Kant himself insists (in a little noticed passage whose importance Zagzebski highlights) that even in the case of mathematical judgments, a position of 'logical egoism' is untenable: one's judgement must be tested by reference to the reason of others, if the individual is to have an 'external criterion of truth' (criterium veritatis externum). ${ }^{10}$ This idea seems to me to be echoed in Kant's Tugendlehre, where parallel considerations apply in the moral sphere, to the deliverances of conscience. At first the picture may look rather subjective and individualistic, with Kant talking of conscience in terms of an 'internal forum' where my acts are brought before the tribunal of reason. But he goes on to argue that it is absurd to think that someone who is accused can be the same person as the one who judges; and hence the subject must think of himself as being judged by another, who is 'an ideal person that reason creates for itself'. Reason is thus abstracted from the contingencies of individual choice, and indeed comes close

7 See Thomas Ritchie (following Thomas Nagel), in From Morality to Metaphysics (Oxford: Oxford University Press, 2012), pp. 96-7 and 101-2.

${ }^{8}$ See Christine Korsgaard, Self-Constitution (Oxford: Oxford University Press, 2009), Chs 1 and 2 .

${ }^{9}$ Zagzebski, Epistemic Authority, p. 23.

${ }^{10}$ Immanuel Kant, Anthropology from a Pragmatic Point of View [Anthropologie in pragmatischer Hinsicht, 1798], transl. R. Louden (Cambridge: Cambridge University Press, 2006), p. 11; cited in Zagzebski, Epistemic Authority, p. 26. 
to the religious idea of a supremely authoritative and rational judge. Notwithstanding this move towards an external criterion, however, Kant (consistently with his general rejection of speculative metaphysics) refuses to be drawn on the question of whether there is any really existing counterpart corresponding to the rational 'Other'. He considers the possibility that a human being is 'entitled, through the idea to which his conscience unavoidably guides him, to assume that such a supreme being actually exists'; but he pulls back from such a conclusion, and ends up saying that the idea of a supreme 'scrutinizer of all hearts' is given 'not objectively, but only subjectively.' ${ }^{11}$ There is no space to evaluate the complexities of Kant's position here, except to observe in passing that his manoeuvre seems in the end to fudge the question of the authority of conscience. For once the actual existence of a supreme external authority is put to one side, it is unclear how the requisite authority can be furnished simply from my own resources. The ambiguity of Kant's legacy here is something moral philosophers are still wrestling with in one form or another. ${ }^{12}$

However that may be, I think it is worth noting that Kant's strictures against 'logical egoism' in some ways prefigure an insight later developed by Ludwig Wittgenstein, who perhaps surprisingly receives only one passing mention in Epistemic Authority. Wittgenstein surely deserves credit for definitively overturning the 'Cartesian' paradigm of the lonely epistemic inquirer who seeks the truth entirely from his or her own interior resources; for Wittgenstein's famous strictures against linguistic privacy entail that no thought or reflection would be possible in the first place unless it operated against the background of a public rule-governed network of language. This is effectively flagged up at the very start of his Philosophical Investigations, where Wittgenstein presents us with Augustine's (on reflection absurd) picture of the infant, fully equipped with reflective thought, who manages to work out what its parents mean when they speak by correlating their utterances and gestures with the various objects they refer to. ${ }^{13}$ But the reality, of course, is that thought

${ }^{11}$ Immanuel Kant, The Metaphysics of Morals: Doctrine of Virtue [Metaphysik der Sitten: Tugendlehre, 1797], ed. M. Gregor (Cambridge: Cambridge University Press, 1996), Part II, $\$ 13$.

${ }^{12}$ For an attempted defence of Kant on this issue, see Korsgaard, Sources of Normativity.

${ }^{13}$ Ludwig Wittgenstein, Philosophical Investigations [Philosophische Untersuchungen, 1953], transl. G. E. M. Anscombe (New York: Macmillan, 1958), \$1, citing Augustine of Hippo, Confessions [Confessiones c. 398], I, 8. 
and linguistic competence develop alongside each other, as the child is gradually inducted into a pre-existing culture. All of us grow towards understanding and awareness out of a position of complete dependency, by being bathed in a milieu of interactive intentionality that we cannot but trust and rely on, as inevitably and spontaneously as we rely on the food we eat or the air we breathe.

This basic climate of trust is by no means suspended even in Descartes' scenario of the lonely meditator setting out on the quest for knowledge; and here Zagzebski seems to me entirely correct in saying that the Cartesian method of doubt should not be construed as a justification of self-reliance. ${ }^{14}$ It is of course true that the perspective adopted in Descartes' most famous work, the Meditations, is that of the solitary thinker, cut off from all contact with the outside world, and immersed in his or her own reflections. But the 'ideas' the meditator reflects on nevertheless have a publicly accessible structure; they are not dependent on the subjective psychological character of the meditator's experience, but relate to those 'immutable and eternal essences' which Descartes insists are quite independent of his own mind. ${ }^{15}$ And the structure that grounds the objectivity of the essences so represented is none other than the mind of God - something as independent of the vagaries of any given individual's psychology as one might wish. Construing Descartes' epistemic stance in a wholly subjectivist way is only possible for the interpreter who implicitly secularizes Cartesian thought. If the stable, divinely underwritten structures of reason and meaning are set aside, and the meditator is left adrift in the isolated world of his own psychology, then it is hardly surprising that the whole Cartesian enterprise looks as if it is supposed to work in an entirely private domain. But that is not Descartes' way. His own philosophical journey is one which, in the very act of striving to break out of his self-imposed ordeal of doubt and uncertainty, comes up against an objective reality that is

${ }_{14}$ Zagzebski, Epistemic Authority, p. 17.

15 René Descartes, Meditations [Meditationes de prima philosophia, 1641], Fifth Meditation, AT VII 64: CSM II 45. In this paper, 'AT' refers to the standard FrancoLatin edition of Descartes by C. Adam \& P. Tannery, Euvres de Descartes (12 vols, revised edn, Paris: Vrin/CNRS, 1964-76); 'CSM' refers to the English translation by J. Cottingham, R. Stoothoff and D. Murdoch, The Philosophical Writings of Descartes, vols I and II (Cambridge: Cambridge University Press, 1985), and 'CSMK' to vol. III, The Correspondence, by the same translators plus A. Kenny (Cambridge: Cambridge University Press, 1991). 
the source not just of his own existence, but of those 'countless ideas' relating to the 'determinate essences, natures or forms', which are 'not invented by me or dependent on my mind. ${ }^{16}$ Even in the solitary mode of the First Meditation, the meditator's method of doubt could not even be formulated on the basis of the kind of private assignment of meanings which Wittgenstein famously attacks. 'Whether I am awake or asleep, two and three added together are five, and a square has no more than four sides. ${ }^{17}$ The objective constraints of language and meaning are in operation from the outset, and become ever more prominent as the argument of the Meditations develops. ${ }^{18}$

What thus emerges, with regard to Descartes, is that properly interpreted he is no advocate of epistemic self-reliance, since he philosophizes from the outset within a rational and objective space of meaning guaranteed by God. And if we tie this result in with the subsequent philosophical developments referred to above, as we trace the story from Kant and finally on to Wittgenstein, there seems to be a remarkable convergence: all three philosophers, properly interpreted, reject doxastic egoism or individualism, and insist that our belief formation must operate in a way that is subject to authoritative and objective constraints. This puts Zagzebski's critique of epistemic selfreliance squarely in line with the thinking of three of the most significant authors to have influenced the shape of modern philosophy.

\section{AUTHORITY AND CONTINGENCY}

Let me now very briefly outline Zagzebski's positive case for relying on authority, as I understand it. Her basic approach may I think be called a Cartesian one, if that often pejoratively employed term may be used for once without prejudice and in a purely methodological sense: her method is to 'proceed wholly from the point of view of the subject a self-reflective person who asks herself how she should get beliefs she

${ }^{16}$ See citation in previous note.

17 Descartes, First Meditation. The doubts subsequently raised by the introduction of the demon are, in my view, much weaker in scope than is often supposed. See John Cottingham, 'The Role of the Malignant Demon', Studia Leibnitiana, Vol. 8 (1976), pp. 257-64, reprinted in G. Moyal (ed.), Descartes: Critical Assessments (London: Routledge, 1991), Vol. II, pp. 129ff.

${ }^{18}$ For more on this, see John Cottingham, Cartesian Reflections (Oxford: Oxford University Press, 2009), esp. Chs. 5, 6, 13. 
accepts upon reflection. ${ }^{19}$ This does not at all imply a commitment to full epistemic self-reliance, which turns out to be an untenable notion (for reasons discussed above); the point, rather, is that any philosophizing has to start from a position of self-reflective consciousness, where a certain degree of trust in oneself, and one's basic faculties, is rational and inescapable. ${ }^{20}$ The next step involves a kind of presumptive epistemic egalitarianism: others clearly have the same basic faculties as I do, and given that I trust my own faculties, then prima facie I should trust theirs. So there is 'a general presumption in favour of the veridicality of the deliverances of the faculties of other persons until shown otherwise.. ${ }^{21}$ Again, this egalitarianism has not a little in common with that of Descartes, who asserts in the opening sentence of the Discourse on the Method that 'good sense is the best distributed thing in the world'. He is no epistemic solipsist, but thinks of his method as available to anyone who is prepared to follow the path of rational inquiry, using the 'natural light' that is the normal birthright of every human being.

So far so good, though as suggested in the previous section I think we may usefully add to this basic premise about self-trust a further rider in the spirit of Wittgenstein. All philosophical inquiry must necessarily operate within an objective 'space of meaning' that has to be taken as given; no conscious self-reflection, even of a purely 'subjective' kind, could occur without presupposing a stable domain of logical and semantic rules. In trusting my faculties, as Zagzebski urges us to do, I have to entrust myself to this domain, in terms of which all my thinking and reflection must necessarily operate.

So far, again, so good. But now comes the problem for any theory which wishes to vindicate reliance on authority: what supports the domain itself, the fundamental set of conceptual structures to which I must entrust myself and which I must take as normative in my reflections? What gives this domain its objective authority over me, and what entitles me to assume that in employing my intellectual faculties and entrusting myself to it I will not be led astray?

Considered as a self-contained puzzle in epistemology, the problem may be intractable (one only has to think of the centuries of inconclusive wrangling over the 'Cartesian circle'). But if one looks at the question

${ }_{19}$ Zagzebski, Epistemic Authority, p. 2.

${ }^{20}$ Zagzebski, Epistemic Authority, p. 3.

${ }^{21}$ Zagzebski, Epistemic Authority, p. 185. 
from a metaphysical standpoint, that is to say, if one puts the epistemic question aside and simply asks how our basic logical and semantic intuitions are pictured within the theistic and the secular worldviews respectively, then a great gulf opens up. The kind of traditional theism espoused by Descartes holds, as we saw in the previous section, that my intellectual faculties give me access to an eternal rational realm of 'essences and forms', held in place by the divine nature, in which my own nature has a dim and imperfect share. When I use my intellect conscientiously, focusing on the 'clear and distinct perceptions' disclosed by the God-given light of reason, I cannot be in error; for 'a reliable mind was God's gift to me. ${ }^{22}$ By contrast, if we move down to the secularist outlook that typically informs present-day philosophizing, the picture is very different. The framework that bestows objectivity is not an eternal framework stemming from divine reason, but is simply the framework of human culture, subject to all the contingency and change that is characteristic of our species and its history. Yet it is by no means clear that this is a worthy object of our trust, given what we know of the mistakes and confusions that have been handed down to us from our forebears, often encrusted with solemn assurances as to their irrevocable validity. Descartes' own warnings are instructive here: though he places his trust in the 'natural light' of reason, which leads him to assent to the clearest perceptions of the God-given intellect, he is anything but trustful of the praejudicia, the preconceived opinion or prejudices handed down from parents and teachers.

It is 'natural' for us to trust our most basic faculties. But 'nature', as Descartes explains in an important passage in the Sixth Meditation, is an ambiguous term. It can mean the authoritative order established by God, and the 'natural' light can mean the divinely instituted intellectual faculty that puts us in touch with that order. But in another sense it can simply mean the human impulse to jump to unwarranted conclusions, or to rely too readily on defective and suspect informants, be they the fluctuating and unreliable testimony of the senses, or the preconceptions we imbibed from our parents and teachers as children. ${ }^{23}$ Trust is warranted only with respect to what is clearly and distinctly perceived

${ }^{22}$ Descartes, Conversation with Burman (1648), AT V 148: CSMK 334. The phrasing is as reported by Burman, but Descartes' own published formulations are closely similar; see Second Replies, AT VIII 144: CSM II 103.

${ }^{23}$ Descartes, Sixth Meditation, AT VII 80-83: CSM II 56-7. 
(which is not to say Descartes thinks it is always easy to establish whether a given perception meets this standard). ${ }^{24}$

Now it is interesting to notice when thinking about the 'natural light' that, for Descartes, there is exact parity between the ratio veri and the ratio boni - the intuitions of the intellect with respect to logic and mathematical truth on the one hand, and with respect to moral goodness on the other. The light of reason discloses reasons of goodness that tell me that a certain value is to be pursued just as clearly and distinctly as it discloses reasons of truth that tell me that a mathematical proposition like 'two plus three is five' is to be affirmed. ${ }^{25}$ How, then, might the moral secularist attempt to vindicate the authority of our basic intuitions in these two types of case?

A possible way forward with respect to our basic logical and mathematical faculties might be to point out that it is not possible coherently to mistrust them. This will not, of course, be a non-circular justification, but at least it brings us up against a bedrock to which there is no alternative; as Thomas Nagel has recently put it, in the case of our most basic logical reasonings, the only thing to think is that I have grasped the truth directly. ${ }^{26}$ In the case of our moral perceptions, by contrast, there seems to be no question of a similar inevitability. And it is at this point that the historical and cultural contingency of our moral systems seems particularly worrying for any defender of an appeal to the legitimacy of authority in the moral sphere. Consider, for example, the recent attempt by John McDowell to establish a normative framework for ethics on the basis of what he calls 'second nature', that is to say, the complex nexus of moral sensibilities and propensities that have arisen through the development of human civilization and culture. For McDowell, these are perfectly 'natural', in the sense that they were developed out of our ordinary contingent activities as biological and social creatures of a certain kind, and hence they do not require us to posit any transcendent or supernatural properties or entities. But he argues that there are nonetheless genuine ethical reasons and requirements, to which we gain access by being inducted as children into a certain ethical culture; and in virtue of the access thereby gained, we do indeed, according to McDowell, become subject to moral requirements and demands. As he puts it:

${ }^{24}$ Descartes, Seventh Replies, AT VII 511: CSM II 348.

${ }^{25}$ Descartes, Fourth Meditation, AT VII 58: CSM II 40.

${ }^{26}$ Thomas Nagel, Mind and Cosmos (Oxford: Oxford University Press, 2012), p. 80. 
the rational demands of ethics are not alien to the contingencies of our life as human beings ... Ordinary upbringing can shape the actions and thoughts of human beings in a way that brings these demands into view. ${ }^{27}$

McDowell's position is a rich and subtle one which it would take us too far round to evaluate here. But the crucial point for present purposes is that, on the McDowell view, the 'reality' of the moral demands to which we are subject is in the end simply a function of a contingently evolved set of human characteristics and dispositions, and a contingently formed culture with a given developmental and social history. There is no further, no more ultimate, moral reality to constrain it or measure it against, and no ultimate telos, no objective goal that represents the final purpose of human ethical life. The developmental history of our species and the genealogy of our ethical culture is a contingent one; it might have been otherwise, and if it had, then, it seems to follow that the relevant ethical 'realities' and 'demands' might have been different. The potentially subversive implications of this kind of picture were acutely discerned by Bernard Williams when he spoke of the 'radical contingency of the ethical. ${ }^{28}$ The problem, in a nutshell, is that once the idea is accepted that the authority and power of the moral demands which seem to call forth our allegiance depends on our past history and the culture into which we happen to have been inducted, then true normativity evaporates. The 'morality system' becomes one among other potential systems, a 'peculiar institution, ${ }^{29}$ whose shackles we may think (as Nietzsche for example did $)^{30}$ that we have reason to shake off in our quest for self-realisation or some other alluring project.

It may seem strange to invoke these secularist pictures of ethics when discussing the views of Zagzebski, who as a theist will be committed,

${ }^{27}$ John McDowell, Mind and World (Cambridge, MA: Harvard University Press, 1996), p. 83.

28 '[A] truthful historical account is likely to reveal a radical contingency in our current ethical conceptions. Not only might they have been different from what they are, but also the historical changes that brought them about are not obviously related to them a way that vindicates them against possible rivals.' Bernard Williams, Truth and Truthfulness (Princeton: Princeton University Press, 2002), Ch. 2, p. 20.

${ }^{29}$ See Bernard Williams, Ethics and the Limits of Philosophy (London: Collins, 1985), Ch. 10.

${ }^{30}$ See Friedrich Nietzsche, Beyond Good and Evil [Jenseits von Gut und Böse, 1886], $\$ 37$ and $\$ 203$. See also John Cottingham, 'The Good Life and the "Radical Contingency of the Ethical"', in D. Callcut (ed.), Reading Bernard Williams (London: Routledge, 2008), Ch. 2, pp. 25-43. 
I take it, to the existence of an eternal, non-contingent, domain of moral reality, and who would therefore repudiate both the Williams-style conception of the 'morality system' as a purely contingent product, and the McDowell-style project of grounding moral normativity in the historical and social facts of human nature and culture. But what these alternative pictures show, I think, is that Zagzebski's argument will be incomplete unless it explicitly moves beyond epistemology to metaphysics, and offers an account of the nature of moral truth, and of our reflective moral beliefs as apt to track that truth. For if the argument for relying on moral authority is conducted in purely epistemic terms (to do with conscientious belief formation), the worry will remain that in enlisting the expertise or even the advice of others, as Zagzebski urges, I may simply be appealing to the propensities and sensibilities of those whose faculties, like mine, have been shaped and formed by induction into a certain culture with contingent historical roots, which might have been otherwise, and which might well come to be superseded. It does not seem enough here to reply that moral authority is justified for the subject by her conscientiously judging that she is more likely to get a belief that will satisfy her future conscientious reflection if she takes the belief on the authority of the others than if she does not. ${ }^{31}$ For the deliverances of further conscientious reflection are surely themselves likely to be shaped by the very system whose authority is here in question. And if this is right, the case for moral authority seems to be threatened. One thinks here of Sabina Lovibond's discussion of how far the self-conscious aspirant to virtue is in a position to respond to challenges about the merits of the currently prevailing process of ethical formation. The worry is that 'a map of the domain of value ... cannot be drawn with any authority in advance of finding answers to the very questions with which it is meant to help us.' ${ }^{32}$

A parallel kind of argument seems to me to apply, mutatis mutandis, to the case of religious authority, where there seems to be an obvious analogue of Bernard Williams' idea of the 'radical contingency of the ethical'. So a devout Roman Catholic from Dublin or Boston, for example, may reflect that had he been born in Bagdad or Tel Aviv, and inducted into an Islamic or a Jewish culture respectively, he might have been inclined

\footnotetext{
${ }^{31}$ See Zagzebski, Epistemic Authority, p. 199.

32 Sabina Lovibond, Ethical Formation (Cambridge Mass: Harvard University Press, 2002), p. 188.
} 
conscientiously to judge that his religious beliefs would be more likely to satisfy his future conscientious reflection by his accepting the authority of the Islamic or Jewish tradition - and all this with the same degree of sincerity and conscientious commitment that characterises his present deference to Catholic authority. In an insightful and humane chapter on 'Trust and Disagreement', Zagzebski does not shrink from confronting the tensions that can arise when I disagree with someone I respect from another faith (for example about the trinitarian nature of God), while at the same time recognizing that I have a prima facie reason to trust their conscientious self-reflection as much as my own. Her answer, if I understand it correctly, is that there is no easy way to resolve 'the antinomy of reasonable disagreement', but that I simply have to balance my estimations of the relative trustworthiness of those of my own faith community, and the likelihood that on reflection I will continue to be able to identify with them, against the possibility that by making radical changes to my emotional and doxastic outlook I can develop a new religious allegiance that will better survive future conscientious selfreflection. Such a change of allegiance might in certain circumstances be the appropriate course, but given the adjustments that would be needed, in most cases the reasonable and conscientious option will be to stay where I am. ${ }^{33}$ Although, in fairness, this is not offered as a full resolution of the antinomy of reasonable disagreement, ${ }^{34}$ I cannot but feel some reservations over the proposed framework of conscientious self-reflection as a means of approaching it. For, as in the moral case, once I fully and deeply acknowledge the contingencies of my present allegiances, and the extent to which my honest self-reflection might have been different had I been inducted into a different culture, then the supposedly objective and rational epistemic basis for my deference to a given religious authority starts to look less secure.

These concerns, such as they are, do not in any way detract from my admiration for Zagzebski's project, or for the superb philosophical finesse with which she executes it. Her powerful exposé of the incoherence of epistemic egoism seems to me unassailable; and as one who shares her particular religious allegiance, I am strongly sympathetic in principle to her aim of vindicating moral and religious authority. She speaks at one point of 'intellectual humility' in connection with trusting a religious

${ }^{33}$ Zagzebski, Epistemic Authority, p. 221.

${ }^{34}$ Zagzebski, Epistemic Authority, Ch. 10, §4, opening paragraph. 
community, ${ }^{35}$ and this seems to me a highly persuasive part of her argument. It would indeed be a strangely perverse kind of arrogance to insist that if I try to figure out what to do all by myself, the outcome is more likely to survive my own future conscientious self-reflection than if I defer to the authority of a community that has flourished for many hundreds of years. ${ }^{36}$ But the problem remains that in deferring to the authority of another I may be allowing myself to be overborne by the power of entrenched tradition or preconceived opinion, or, more radically, that the very sensibilities and responses that incline me to such deference may themselves have been shaped by induction into the tradition whose authority is in question.

The best way to break out of this impasse seems to me to proceed not by further epistemic theorizing but by action; that is, to follow the 'Pascalian' ${ }^{37}$ suggestion of ceasing to be preoccupied from an external standpoint with beliefs and their justification, and instead moving inside a faith tradition - entrusting oneself to a structure of communal praxis that fosters moral and spiritual enrichment, opening the way to new and deeper kinds of experience which, if all goes well, I may come to see retrospectively as validating my act of trust. Here I would wholeheartedly agree with the more pragmatic or practically oriented note sounded by Zagzebski towards the end of her remarkable book, in the chapter on religious authority:

There are other natural desires [apart from the desire for truth] that can be better satisfied by participation in a wisdom community than on one's own. These desires include the desire to know and to do the good, to acquire not just knowledge, but understanding, to learn patterns of living and principles of action that result in a more integrated self, to be surrounded by grace and beauty, and to experience the delights of living among persons whose own pursuit of these ends enhances one's own. ${ }^{38}$

This beautifully expressed set of aspirations exemplifies the kind of goal that cannot plausibly be achieved by a 'do-it-yourself' approach. Trust, to come back full circle to the point with which we started, is always open to abuse, and entrusting oneself to a tradition, or committing oneself to an individual or to a community, is never without risk. But without

\footnotetext{
${ }^{35}$ Zagzebski, Epistemic Authority, p. 199.

${ }^{36}$ Cf. Zagzebski, Epistemic Authority, p. 148.

${ }^{37}$ Cf. Blaise Pascal, Pensées [1670], ed. L. Lafuma (Paris: Seuil, 1962), no 418.

${ }^{38}$ Zagzebski, Epistemic Authority, p. 201.
} 
such trust, we may be cutting ourselves off from the very possibility of arriving at the evidence needed to justify that trust, and of achieving the spiritual goods that vindicate it. If that is a paradox, it is a paradox which flows from the inescapable dependency that is part of what it is to be human. ${ }^{39}$

${ }^{39}$ I am most grateful to Fiona Ellis for helpful discussion of an earlier draft of this paper. 